\title{
Bubble CPAP: Not All Bubbling Is Good Bubbling
}

Since its introduction over 30 years ago, ${ }^{1}$ bubble CPAP has become an important part of the management of neonatal respiratory distress syndrome. Similar to "ventilatorderived" or "machine-derived" CPAP devices, bubble CPAP devices apply pressure to the neonatal respiratory system via nasal prongs placed into the infant's nostrils, forming a tight seal to minimize leak. On the other hand, bubble CPAP devices are much simpler than ventilatorderived CPAP, often consisting only of humidified bias flow being delivered into the inspiratory limb, and the CPAP level set based on the distance the expiratory limb of the circuit is submerged into a water seal chamber. The simplicity of this system makes it attractive to many centers, especially resource-limited neonatal units in developing countries. ${ }^{2}$

Bubble CPAP also differs from ventilator-derived CPAP mechanistically. The mean pressure applied to the infant's airway in bubble CPAP is not constant, as it is in ventilator-derived systems, but, rather, resonant, with the airway pressure actually fluctuating approximately $4 \mathrm{~cm} \mathrm{H}_{2} \mathrm{O}$ around the mean. ${ }^{3}$ This resonance results from the bubbling that occurs when the bias flow reaches the water seal chamber. For example, in a bubble CPAP system in which the expiratory limb of the circuit is submerged $5 \mathrm{~cm} \mathrm{H}_{2} \mathrm{O}$, the pressure applied to the airway may actually be "oscillating" between 3 and $7 \mathrm{~cm} \mathrm{H}_{2} \mathrm{O}$. These pressure swings are caused by pressure amplitudes created by the bubbling in the water seal chamber that reflects back through the expiratory limb of the circuit. Several studies have suggested this "noise" contributes to alveolar recruitment and maintenance of airway patency, and is thus likely responsible for some of the beneficial effects of bubble CPAP on gas exchange, lung volumes, and outcomes that have been reported in infants with neonatal respiratory distress syndrome. ${ }^{4-6}$ Further, this effect seems to be most pronounced early after birth, when compliance is low and the oscillating pressure amplitudes are minimally dampened as they are transmitted through the respiratory system. ${ }^{3}$

In this month's issue of ResPiRATORY CARE, Youngquist and colleagues report an elegant set of experiments evaluating the effect of a different kind of "noise" on the pressure delivered to the airway in infants receiving bubble CPAP. ${ }^{7}$ For most infants receiving positive-pressure ventilation, whether from traditional mechanical ventilators or bubble CPAP devices, condensate forms in the expiratory limb of the circuit as warm humidified gas is exposed to room temperature tubing. As the authors note, if there is a low point in the expiratory tubing, a considerable amount of condensate will form and "bounce/bubble" around in the tubing as more gas flows past. In traditional mechanical ventilators, this "bubbling" can lead to excessive activation of the flow trigger and lead to hyperventilation. $^{8}$

See the Original Study on Page 1840

To my knowledge, prior to these experiments by Youngquist et al there were no studies examining the effect of this condensate on bubble CPAP devices. Using a neonatal test lung configured to simulate the physiology of an extremely-low-birth-weight infant and a sophisticated artificial nasopharynx model produced to simulate the high resistance of this portion of the neonatal respiratory system, the authors measured the rate of fluid accumulation with the bubble CPAP system and the airway pressures generated at different fluid accumulation levels in the expiratory limb of the circuit. At CPAP of $5 \mathrm{~cm} \mathrm{H}_{2} \mathrm{O}$ and flow of $8 \mathrm{~L} / \mathrm{min}$ they report a steady rate of condensate accumulation of $3.8 \mathrm{~mL} / \mathrm{h}$. Airway pressures did not seem to be affected by $<5 \mathrm{~mL}$ of fluid accumulation, but as condensate volumes increased to $10 \mathrm{~mL}, 15 \mathrm{~mL}$, and $20 \mathrm{~mL}$, there was a 1.5-, 2-, and 3-fold increase in the amplitudes of the pressure oscillations measured at the airway. Specifically, the amplitudes increased from approximately $3 \mathrm{~cm} \mathrm{H}_{2} \mathrm{O}$ at $0-5 \mathrm{~mL}$ of fluid accumulation to as high as $8-10 \mathrm{~cm} \mathrm{H}_{2} \mathrm{O}$ at $20 \mathrm{~mL}$ of fluid accumulation. In practical terms, an infant receiving bubble CPAP set at $8 \mathrm{~cm} \mathrm{H}_{2} \mathrm{O}$ could be receiving pressure oscillations fluctuating between 3 and $13 \mathrm{~cm} \mathrm{H}_{2} \mathrm{O}$ at the airway, and in infants with very poor lung compliance, much of this pressure will be transmitted to the alveoli. While the small amount of "noise" generated by the bubbles in the water seal chamber could be helpful, the larger pressure swings generated by this unintended fluid accumulation has more potential to be harmful.

While no artificial model will simulate all of the subtleties and nuances of a living infant with neonatal respiratory distress syndrome, the novel model created by these authors is impressive and accounts for most if not all of the important physiologic conditions present in these patients. Their results should therefore be considered valid, and 
neonatologists who regularly use bubble CPAP should be more aware of this problem. As the authors note, many bubble CPAP devices do not have the degree of safety features and alarms present in ventilator-derived CPAP devices. The authors conclude their set of experiments by demonstrating that the addition of a pressure-relief valve in the bubble CPAP circuit can attenuate the large pressure swings caused by the accumulated condensate. These devices, however, should not take the place of strict surveillance of the bubble CPAP circuit. Simple hourly observation and, if necessary, emptying of the condensate from the expiratory limb of the circuit by the bedside nurse or respiratory therapist should effectively limit this unwanted additional "noise."

Youngquist and colleagues should be commended for their sophisticated approach to confirming what many other neonatologists and pediatric intensivists have suspected but never put in the effort to formally study. I hope that their work not only increases awareness of this one potential problem but also inspires other academic clinicians to look for other types of "noise" in their own ICUs and put in the efforts to determine its effect on their fragile patients.

The author has disclosed no conflicts of interest.

Correspondence: Christopher W Mastropietro MD, Division of Critical Care, Department of Pediatrics, Riley Hospital for Children, 705 Riley Hospital Drive, RI 2117, Indianapolis IN 46202. E-mail: cmastrop@ iupui.edu.

DOI: $10.4187 /$ respcare. 02872

\author{
Christopher W Mastropietro MD \\ Division of Critical Care \\ Department of Pediatrics \\ Riley Hospital for Children \\ Indiana University School of Medicine \\ Indianapolis, Indiana
}

\section{REFERENCES}

1. Wung JT, Driscoll JM Jr, Epstein RA, Hyman AI. A new device for CPAP by nasal route. Crit Care Med 1975;3(2):76-78.

2. Koyamaibole L, Kado J, Qovu JD, Colquhoun S, Duke T. An evaluation of bubble-CPAP in a neonatal unit in a developing country: effective respiratory support that can be applied by nurses. J Trop Pediatr 2006;52(4):249-253.

3. Pillow JJ, Hillman N, Moss TJ, Polglase G, Bold G, Beaumont C, et al. Bubble continuous positive airway pressure enhances lung volume and gas exchange in preterm lambs. Am J Respir Crit Care Med 2007;176(1):63-69.

4. Narendran V, Donovan EF, Hoath SB, Akinbi HT, Steichen JJ, Jobe AH. Early bubble CPAP and outcomes in ELBW preterm infants. J Perinatol 2003;23(3):195-199.

5. Nowadzky T, Pantoja A, Britton JR. Bubble continuous positive airway pressure, a potentially better practice, reduces the use of mechanical ventilation among very low birth weight infants with respiratory distress syndrome. Pediatrics 2009;123(6):1534-1540.

6. Gupta S, Sinha SK, Tin W, Donn SM. A randomized controlled trial of post-extubation bubble continuous positive airway pressure versus Infant Flow Driver continuous positive airway pressure in preterm infants with respiratory distress syndrome. J Pediatr 2009;154(5): 645-650.

7. Youngquist TM, Richardson CP, DiBlasi RM. Effects of condensate in the exhalation limb of neonatal circuits on airway pressure during bubble CPAP. Respir Care 2013;58(11):1840-1846.

8. Sassoon CSH. Triggering of the ventilator in patient-ventilator interactions. Respir Care 2011;56(1):39-48; discussion: 48-51. 